\title{
Docencia innovadora en Historia Antigua y Medieval (Grado en Historia del Arte). Aplicación de un Ciclo de Mejora en el Aula
}

\section{Innovative teaching in Ancient and Medieval History (Degree in Art History). Application of an Improvement Cycle in the Classroom}

DANIEL LEón ARdoy

ORCID: https://orcid.org/0000-0003-4973-2520

Universidad de SevillaDepartamento

de Historia Antigua

dlardoy@us.es

DOI: http://dx.doi.org/10.12795/9788447231003.038

Pp.: 799-817 


\section{Descripción breve del contexto}

La asignatura Historia Antigua y Medieval se trata de una materia de formación básica, y por tanto obligatoria, inserta en el primer cuatrimestre del primer curso del Grado en Historia del Arte. Sus objetivos principales son la adquisición de conocimientos detallados sobre dichos periodos históricos para poder contextualizar de manera óptima aquellos conocimientos netamente artísticos que el alumnado desarrolle en otras asignaturas específicamente relacionadas con la Historia del Arte y la obtención de conciencia crítica al respecto de las conexiones tan estrechas entre ambas disciplinas del ámbito de las humanidades.

La asignatura tiene una duración de seis créditos de clases teórico-prácticas divididos de la siguiente forma: en los tres primeros créditos se imparten los contenidos referentes a Historia Antigua -a saber: el Próximo Oriente Asiático, el Egipto faraónico, la Grecia Antigua y la Roma Antigua- y en los tres últimos aquellos relativos a Historia Medieval -a saber: Alta Edad Media, Plena Edad Media, Baja Edad Media y Renacimiento-. Precisamente, esta extensísima cronología de la materia (más de cuatro mil años de historia) hace que sea percibida por gran parte de los discentes como una de las más inabarcables e inasumibles de todo el grado, como lamentablemente demuestra el índice anual de aprobados y suspensos. De hecho, de las ciento treinta y tres personas matriculadas en el grupo al que imparto las clases, más de ochenta son repetidores de cursos académicos anteriores.

A esto debe sumarse tanto el perfil de los estudiantes -generalmente, jóvenes recién egresados de bachillerato y, todavía, sin experiencia universitaria- como la anómala situación pandémica que nos ha tocado vivir durante, al menos, este curso académico 2020-2021, con todo lo que ello conlleva sobre todo para los alumnos (protocolos 
sanitarios en el aula, adaptación a modalidades de semipresencialidad y/u online, cuadros de estrés y ansiedad, etc.). Además, en calidad de contratado predoctoral FPU, es el primer año que doy clase, en general, y esta materia, en particular. En definitiva, aunque, a mi parecer, sea una asignatura fascinante, es igualmente compleja en su ejecución.

\section{Diseño previo del Ciclo de Mejora en el Aula (CIMA)}

\section{Mapa de contenidos y problemas claves}

Previamente a la aplicación práctica del CIMA, desde el Curso General de Docencia Universitaria (CGDU) se nos instó a realizar un diseño previo del mismo, donde incluyéramos pormenorizadamente no sólo la descripción de aquellas actividades de contraste destinadas a hacer evolucionar los modelos cognitivos previos de los discentes hacia un conocimiento adecuado, sino también el planteamiento de aquel modelo metodológico posible que nos viésemos capacitados a poder llevar a cabo a lo largo de las ocho horas de duración del CIMA. Asimismo, puesto que los tres factores o pilares fundamentales sobre los que se fundamenta la docencia -a saber: metodología, contenidos y evaluación- son interdependientes entre sí, en dicho diseño se incorporó un mapa de contenidos, primando aquellos contenidos estructurantes del bloque de la asignatura sobre el que se centraría el ciclo. Por supuesto, éstos tendrían que venir precedidos de una serie de problemas o preguntas claves, también reflejados en el mapa (Figura 1), que activaran las ideas de los estudiantes.

Como se podrá haber comprobado con el anterior párrafo -y como se seguirá demostrando a lo largo de todo el 
capítulo- la innovación docente no es improvisada: implica una exhaustiva planificación y reflexiones epistemológicas que desafían todos aquellos prejuicios y reticencias a transformar las clases universitarias convencionales en aras del beneficio académico y personal de los discentes (Karm, 2010).

En este caso, la aplicación del CIMA coincidió plenamente con el segundo tema de la materia, el Egipto faraónico antiguo. Se trata de una parcela histórica de la que, aunque presenta multitud de datos y conceptos que podrían catalogarse como contenidos secundarios, se pueden extraer otros tipos de contenidos, como procedimientos intelectuales y actitudinales. De hecho, esto es lo que he tratado de plasmar en el mapa: centrar la atención del alumnado, y la mía propia, en dichos contenidos intelectuales y actitudinales (a los que he clasificado jerárquicamente como estructurantes).

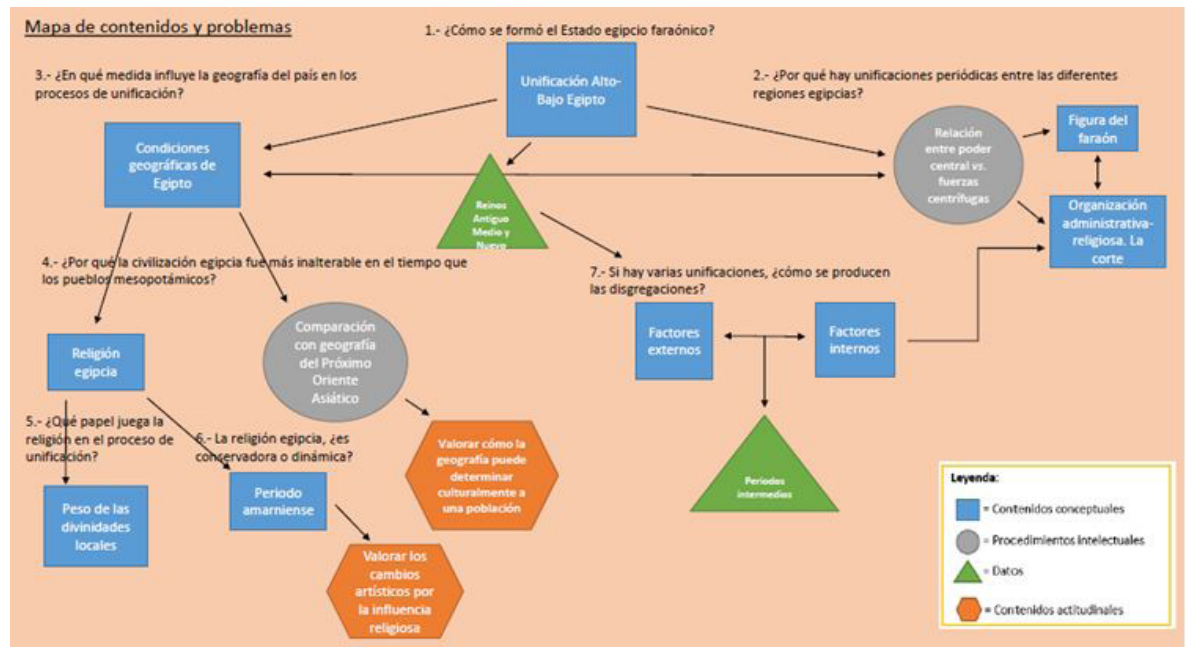

Figura 1. Mapa de contenidos y problemas claves

Ciclos de Mejora en el Aula (2020). Experiencias de Innovación Docente de la US Esta obra se distribuye con la licencia Creative Commons 


\section{Modelo metodológico posible y secuencia de actividades programadas}

Dado los buenos resultados que obtuve en la realización del primer CIMA, el pasado mes de marzo, aplicando un "modelo metodológico activo, constructivista e investigativo" (De Alba y Porlán, 2017), en el que los estudiantes fueron elaborando el conocimiento de una forma activa, dinámica y entretenida, en este segundo CIMA he tenido el propósito de llevar a cabo un modelo muy similar, pero adecuándome a la nueva asignatura, a los nuevos contenidos y a los conocimientos previos de los discentes, testados a través del cuestionario de diagnóstico inicial que detallaremos en el siguiente subapartado.

Durante las primeras semanas lectivas de este primer cuatrimestre (curso académico 2020-2021) previas a la aplicación del CIMA, he intentado igualmente poner en práctica aquellos aspectos sobre los que hemos estado incidiendo en las diferentes sesiones del CGDU. Como los contenidos establecidos para esta asignatura son amplísimos y enormemente densos, he tratado, en la medida de lo posible, hacer lo más amenas las clases mediante el recurso de mapas, comentarios de textos, análisis de fotografías, etc. Sin embargo, no podría considerar el empleo de dichos recursos como "actividades de contraste" pues, en la mayoría de las ocasiones, era yo mismo el que comentaba los mapas, los textos y las imágenes, alternando con algunas preguntas lanzadas hacia los alumnos (que, por supuesto, casi nunca tenían respuesta).

Por ello, creo que en esas dos primeras semanas de docencia he realizado un modelo metodológico a medio camino entre el transmisivo y el constructivista. Es decir, el denominado "modelo metodológico de resolución de problemas cerrados por los alumnos" (De Alba y Porlán, 2017), en el que las ideas de éstos son asumidas por el docente 
como errores a corregir y en el que se establece una interacción parcial entre ambas figuras (ciertamente, así lo he sentido).

No obstante, con la elaboración del mapa de contenidos problematizados y de la consiguiente secuencia de actividades, traté de evolucionar este modelo de resolución de problemas cerrados a un modelo puramente constructivista.

A grandes rasgos, mi modelo metodológico posible (Figura 2) ha contenido las siguientes fases esenciales:

- PR = Pregunta previa que me introduzca a:

- IPA = Ideas previas de los alumnos. Estas ideas no me sirven únicamente para hacerme una idea del nivel que tienen los estudiantes sobre conocimientos teóricos particulares. También son una importante herramienta para conseguir que el alumnado piense sobre cuestiones que pueden surgirles en el día a día. En realidad, con la realización del cuestionario de diagnóstico inicial ya pueden conocerse dichas ideas previas, pero creo que ponerlas en común con los alumnos sería una buena actividad de introducción a las actividades de contraste.

- $A C=$ Una vez se conozcan las ideas de los alumnos, se realizarán actividades de contraste destinadas a que dichas ideas previas evolucionen hacia la asunción del conocimiento teórico correcto asociado al contenido que se quiere aprender.

- IFA = Ideas finales de los alumnos. Tras realizar dichas actividades, se vuelve a plantear a los estudiantes el problema inicial para comprobar si sus ideas previas han cambiado y si han comprendido esta evolución.

Ciclos de Mejora en el Aula (2020). Experiencias de Innovación Docente de la US Esta obra se distribuye con la licencia Creative Commons 
- PRC = Pregunta conclusiva. Plantear un nuevo interrogante al final de la sesión para que sea resuelto en la siguiente. De este modo, creo que se puede mantener el interés del alumno por la materia a lo largo de los días.

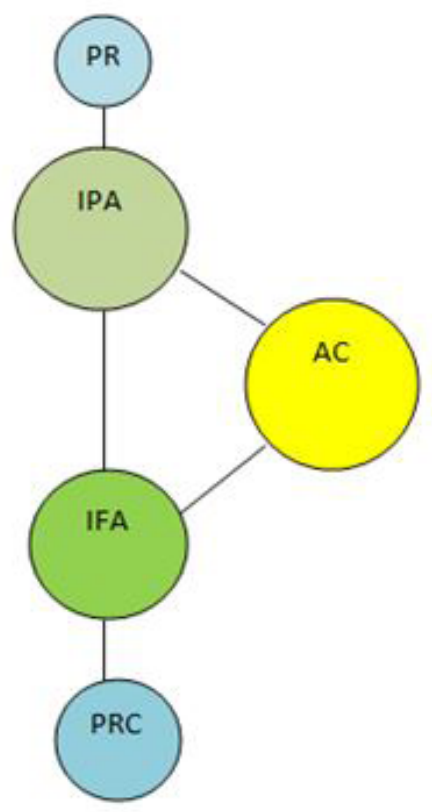

Figura 2. Modelo metodológico posible

En lo que respecta al diseño de la secuencia de actividades de contraste, como el CIMA se realizó durante seis sesiones consecutivas, para no extenderme en demasía, voy a centrarme en detallar a continuación una de estas sesiones, la llevada a cabo el miércoles 21 de octubre, de 1 hora y 30 minutos de duración, a la que tomaré como ejemplo.

Ciclos de Mejora en el Aula (2020). Experiencias de Innovación Docente de la US Esta obra se distribuye con la licencia Creative Commons 
Tabla 1. Primera sesión: planteamiento de problema previo

\begin{tabular}{|l|l|l|l|}
\hline $\begin{array}{l}\text { Fase del modelo } \\
\text { metodológico } \\
\text { posible a la que } \\
\text { pertenece: PR }\end{array}$ & $\begin{array}{l}\text { No de } \\
\text { orden de la } \\
\text { actividad: } 1\end{array}$ & $\begin{array}{l}\text { Nombre de } \\
\text { la actividad: } \\
\text { Planteamiento de } \\
\text { problema previo }\end{array}$ & Tiempo: 2 minutos \\
\hline $\begin{array}{l}\text { Desarrollo concreto } \\
\text { y detallado de la } \\
\text { actividad }\end{array}$ & $\begin{array}{l}\text { Esta actividad coincide plenamente con la primera fase del } \\
\text { modelo metodológico posible, a saber, el establecimiento } \\
\text { por mi parte de un problema previo que haga pensar al } \\
\text { alumnado. En este caso, dicho problema ya fue presentado } \\
\text { a los discentes en el cuestionario de diagnóstico inicial. } \\
\text { Aunque me haya leído previamente sus ideas previas al } \\
\text { respecto, me gustaría iniciar la sesión planteándoles la } \\
\text { siguiente pregunta -de la que partirán los contenidos que } \\
\text { se verán en clase-: “Cómo crees que se formó el Estado } \\
\text { egipcio faraónico?". }\end{array}$ \\
\hline Recursos necesarios & $\begin{array}{l}\text { No se necesita ningún recurso adicional (aparte del } \\
\text { Blackboard Collaborate Ultra). }\end{array}$ \\
\hline
\end{tabular}

Tabla 2. Primera sesión: ideas previas del alumnado

\begin{tabular}{|l|l|l|l|}
\hline $\begin{array}{l}\text { Fase del modelo } \\
\text { metodológico } \\
\text { posible a la que } \\
\text { pertenece: IPA }\end{array}$ & $\begin{array}{l}\text { No de orden de } \\
\text { la actividad: } 2\end{array}$ & $\begin{array}{l}\text { Nombre de la } \\
\text { actividad: Debate y } \\
\text { puesta en común } \\
\text { de conocimientos } \\
\text { previos }\end{array}$ & $\begin{array}{l}\text { Tiempo: } 28 \\
\text { minutos }\end{array}$ \\
\hline $\begin{array}{l}\text { Desarrollo } \\
\text { concreto y } \\
\text { detallado de la } \\
\text { actividad }\end{array}$ & $\begin{array}{l}\text { Generación de un debate donde los alumnos, de forma } \\
\text { ordenada y por turnos de palabras, expongan sus ideas sobre la } \\
\text { cuestión planteada. Previamente, les entregaré su cuestionario } \\
\text { de diagnóstico inicial para generar dicho debate con mayor } \\
\text { facilidad. Una vez las vayan comentado, iré apuntándolas en } \\
\text { la pizarra para hacer una puesta en común. Se pedirá a los } \\
\text { discentes que hagan lo mismo en sus respectivos soportes de } \\
\text { escritura. } \\
\text { Puesto que, con total seguridad, en un primer momento será } \\
\text { complicado iniciar la actividad (debido a la vergüenza o al } \\
\text { miedo de dar una respuesta errónea), iré dando la palabra en } \\
\text { primer lugar a los estudiantes que observe más participativos } \\
\text { y, posteriormente, iré involucrando a aquellos alumnos más } \\
\text { tímidos. }\end{array}$ \\
\hline
\end{tabular}

Ciclos de Mejora en el Aula (2020). Experiencias de Innovación Docente de la US Esta obra se distribuye con la licencia Creative Commons Reconocimiento-NoComercial-SinObraDerivada Internacional (CC BY-NC-ND 4.0.) 


\begin{tabular}{|l|l|}
\hline & $\begin{array}{l}\text { Al ser un grupo de tarde, normalmente vienen estudiantes de } \\
\text { edad más avanzada que suelen ser más participativos que } \\
\text { los jóvenes. Seguramente sean aquéllos los que se atrevan } \\
\text { a hablar en primer lugar. Hay que tener en cuenta que esta } \\
\text { asignatura es del primer cuatrimestre del primer curso del } \\
\text { Grado: todavía no se conocen entre ellos y acaban de ingresar } \\
\text { en la universidad, por lo que no creo que sean demasiado } \\
\text { participativos (como he podido comprobar durante las dos } \\
\text { primeras semanas de clase). }\end{array}$ \\
\hline $\begin{array}{l}\text { Recursos } \\
\text { necesarios }\end{array}$ & $\begin{array}{l}\text { Blackboard Collaborate Ultra, pizarra, tiza y soportes varios de } \\
\text { escritura (folios, ordenadores, tablets, etc.). }\end{array}$ \\
\hline
\end{tabular}

Tabla 3. Primera sesión: actividad de contraste núm. 1

\begin{tabular}{|l|l|l|l|}
\hline $\begin{array}{l}\text { Fase del modelo } \\
\text { metodológico posible } \\
\text { a la que pertenece: AC }\end{array}$ & $\begin{array}{l}\text { No de orden de la } \\
\text { actividad: } 3\end{array}$ & $\begin{array}{l}\text { Nombre de la actividad: } \\
\text { Explicación mediante } \\
\text { comentario de imágenes }\end{array}$ & $\begin{array}{l}\text { Tiempo: } 30 \\
\text { minutos }\end{array}$ \\
\hline $\begin{array}{l}\text { Desarrollo concreto } \\
\text { y detallado de la }\end{array}$ & $\begin{array}{l}\text { En primer lugar, compartiré en el Collaborate (para que } \\
\text { también puedan verlo desde casa) dos imágenes: } \\
\text { 1. Mapa del territorio egipcio sin resaltar los accidentes } \\
\text { geográficos de la región (a excepción del río Nilo). En } \\
\text { este mapa se señalizan las dos regiones del país, el Alto } \\
\text { y el Bajo Egipto, y su ubicación con respecto al Nilo. } \\
\text { 2. La Paleta de Narmer: placa de pizarra con bajorrelie- } \\
\text { ves donde se observa el uso de la violencia física por } \\
\text { parte del primer unificador de Egipto (Narmer) como } \\
\text { elemento de formación del Estado. } \\
\text { Antes de compartir las imágenes, les daré algunas } \\
\text { preguntas para encauzar sus conocimientos: “Cómo } \\
\text { pensáis que se divide el valle del Nilo?, ¿Podrías realizar } \\
\text { una descripción de las ilustraciones de la paleta de } \\
\text { Narmer?". Lo que pretendo es que los alumnos vayan } \\
\text { analizando (por supuesto, con mi ayuda) los diferentes } \\
\text { elementos que vemos tanto en el mapa como en la paleta } \\
\text { relacionados con la formación del Estado egipcio (el Nilo } \\
\text { como eje vertebrador, la distinción geográfica entre Alto y } \\
\text { Bajo Egipto y el uso de la violencia por parte de personajes } \\
\text { individuales). Primero de forma individual y después se } \\
\text { cotejan las ideas por parejas. Por último, puesta en común } \\
\text { de las conclusiones de los discentes. }\end{array}$ \\
\hline $\begin{array}{l}\text { Blackboard Collaborate Ultra, las dos imágenes (en jpg o } \\
\text { en pdf), pizarra, tiza y soportes de escritura varios (folios, } \\
\text { ordenadores, tablets, etc.). }\end{array}$ \\
\hline
\end{tabular}

Ciclos de Mejora en el Aula (2020). Experiencias de Innovación Docente de la US Esta obra se distribuye con la licencia Creative Commons 
Tabla 4. Primera sesión: actividad de contraste núm. 2

\begin{tabular}{|c|c|c|c|}
\hline $\begin{array}{l}\text { Fase del modelo } \\
\text { metodológico } \\
\text { posible a la que } \\
\text { pertenece: AC }\end{array}$ & $\begin{array}{l}\text { de orden de } \\
\text { actividad: } 4\end{array}$ & $\begin{array}{l}\text { Nombre de la } \\
\text { actividad: Análisis } \\
\text { de texto (Hdt. } \\
\text { II.99) }\end{array}$ & Tiempo: 20 minutos \\
\hline $\begin{array}{l}\text { Desarrollo } \\
\text { concreto y } \\
\text { detallado de la } \\
\text { actividad }\end{array}$ & \multicolumn{3}{|c|}{$\begin{array}{l}\text { Durante estos } 20 \text { minutos, dejaré que los estudiantes lean, } \\
\text { tanto presencialmente como desde sus casas, un breve texto } \\
\text { de Heródoto sobre el rey Narmer/Menes, primer faraón de } \\
\text { Egipto, para que señalen las semejanzas que presenta con } \\
\text { la actuación de los jefes o cabecillas de las ciudades-estado } \\
\text { sumerias. Previamente, les dejaré la siguiente pregunta: } \\
\text { “Qué semejanzas veis entre la actuación de Narmer } \\
\text { y la de los reyes sumerios?". Este texto lo habré colgado } \\
\text { previamente en Enseñanza Virtual para que todos tengan } \\
\text { acceso a él. No obstante, lo proyectaré durante la actividad. } \\
\text { Asimismo, pretendo que busquen información sobre la } \\
\text { procedencia de Narmer (Alto Egipto) y la ubicación de la } \\
\text { ciudad que se menciona en el texto: Menfis (Bajo Egipto). } \\
\text { Esto servirá para que se den cuenta que la formación del } \\
\text { Estado fue desde el Alto Egipto al Bajo Egipto, del Sur al } \\
\text { Norte. } \\
\text { Los alumnos deberán entregarme las anotaciones que } \\
\text { hayan extraído del texto. }\end{array}$} \\
\hline $\begin{array}{l}\text { Recursos } \\
\text { necesarios }\end{array}$ & \multicolumn{3}{|c|}{$\begin{array}{l}\text { Blackboard Collaborate Ultra, soportes de escritura varios } \\
\text { (preferiblemente ordenadores y tablets para que puedan } \\
\text { buscar la información. Si no tienen, también pueden } \\
\text { buscarla con sus teléfonos móviles). }\end{array}$} \\
\hline
\end{tabular}

Tabla 5. Primera sesión: ideas finales del alumnado

\begin{tabular}{|l|l|l|l|}
\hline $\begin{array}{l}\text { Fase del modelo } \\
\text { metodológico } \\
\text { posible a la que } \\
\text { pertenece: IFA }\end{array}$ & $\begin{array}{l}\text { No de orden de } \\
\text { la actividad: } 5\end{array}$ & $\begin{array}{l}\text { Nombre de } \\
\text { la actividad: } \\
\text { Comparación de } \\
\text { ideas previas } \\
\text { con las actuales }\end{array}$ & Tiempo: 8 minutos \\
\hline $\begin{array}{l}\text { Desarrollo concreto } \\
\text { y detallado de la } \\
\text { actividad }\end{array}$ & $\begin{array}{l}\text { Cotejar las ideas previas de los discentes ante la pregunta } \\
\text { ¿Cómo crees que se formó el Estado egipcio faraónico?" } \\
\text { con los conocimientos desarrollados tras las actividades } \\
\text { de contraste planteadas. }\end{array}$ \\
\hline $\begin{array}{l}\text { Recursos } \\
\text { necesarios }\end{array}$ & $\begin{array}{l}\text { Pizarra, tiza y soportes de escritura varios (folios, } \\
\text { ordenadores, tablets, etc.). }\end{array}$ \\
\hline
\end{tabular}

Ciclos de Mejora en el Aula (2020). Experiencias de Innovación Docente de la US Esta obra se distribuye con la licencia Creative Commons 
Tabla 6. Primera sesión: planteamiento de pregunta conclusiva

\begin{tabular}{|l|l|l|l|}
\hline $\begin{array}{l}\text { Fase del modelo } \\
\text { metodológico } \\
\text { posible a la que } \\
\text { pertenece: PRC }\end{array}$ & $\begin{array}{l}\text { No de orden de } \\
\text { la actividad: } 6\end{array}$ & $\begin{array}{l}\text { Nombre de } \\
\text { la actividad: } \\
\text { Planteamiento de } \\
\text { pregunta conclusiva }\end{array}$ & Tiempo: 2 minutos \\
\hline $\begin{array}{l}\text { Desarrollo concreto } \\
\text { y detallado de la } \\
\text { actividad }\end{array}$ & $\begin{array}{l}\text { Para mantener el interés del alumno hasta la siguiente } \\
\text { sesión les lanzaré la siguiente pregunta: “¿Pensáis que } \\
\text { todas las unificaciones entre Alto y Bajo Egipto procederán } \\
\text { del Sur? Buscad información al respecto y lo analizamos } \\
\text { mañana". }\end{array}$ \\
\hline Recursos necesarios & $\begin{array}{l}\text { No se necesita ningún recurso adicional (aparte del } \\
\text { Blackboard Collaborate Ultra). }\end{array}$ \\
\hline
\end{tabular}

\section{Cuestionarios de diagnóstico inicial y final}

Como ya he mencionado, para realizar un seguimiento de la evolución de los modelos cognitivos previos de los estudiantes hacia el conocimiento esperado, les pasé dos cuestionarios voluntarios de diagnóstico idénticos y puestos en relación con los contenidos y problemas claves fijados en el mapa (Figura 1). El cuestionario inicial lo pasé la semana anterior a la aplicación del CIMA y el final durante la última sesión del ciclo (siendo en sí mismo una actividad de contraste más). En total, participaron anónimamente doce alumnos en la actividad, otorgando a cada uno de ellos un número del 1 al 12. Ambos cuestionarios contenían las siguientes preguntas:

1. ¿Cómo crees que se formó el Estado egipcio faraónico?

2. ¿Por qué hay unificaciones periódicas entre las diferentes regiones egipcias?

3. ¿En qué medida piensas que la geografía de la región influye en los procesos de unificación?

4. ¿Por qué la civilización egipcia fue más inalterable en el tiempo que los pueblos mesopotámicos?

5. 5.- ¿De dónde proceden los antiguos griegos?

Ciclos de Mejora en el Aula (2020). Experiencias de Innovación Docente de la US Esta obra se distribuye con la licencia Creative Commons 


\section{Aplicación del Ciclo de Mejora en el Aula}

\section{Relato resumido de las sesiones: el diario de sesiones}

Gracias al empleo de un diario de sesiones en el que iba anotando, sesión por sesión, tanto una descripción minuciosa sobre la puesta en práctica de las actividades de contraste como una valoración personal y emocional, he podido analizar qué elementos han funcionado, cuáles debo mejorar de cara a un futuro CIMA y realizar una visión resumida y general sobre todo el proceso.

Ciertamente, aunque en la primera sesión sí que me encontré bastante nervioso debido a problemas que no había tenido en cuenta en el diseño del CIMA, como, por ejemplo, la posible extralimitación temporal de las actividades de contraste y la imposibilidad de elaborar grupos reducidos de trabajo presencial por los protocolos sanitarios en el aula a causa del SARS-CoV-2, para las siguientes sesiones tomé nota de todos estos inconvenientes, pudiendo llevarlas a cabo sin grandes dificultades ni sobresaltos.

A grandes rasgos, me ha resultado una experiencia muy gratificante y altamente positiva. Los alumnos han participado bastante y se han generado debates muy interesantes. Si tuviera que quedarme con alguna sesión en concreto, me quedaría con la quinta por tener lugar en ella las actividades de contraste que han resultado más motivadoras (análisis de noticias actuales referentes a nuevos descubrimientos del Antiguo Egipto y comentario de texto histórico muy vinculado con el grado en el que imparto la asignatura -Historia del Arte- apoyado en la comparación de imágenes proyectadas). Tanto los estudiantes como yo mismo, nos encontrábamos ya a gusto en esta dinámica. Creo que estas actividades de contraste han funcionado tan bien porque se ha logrado captar el interés

Ciclos de Mejora en el Aula (2020). Experiencias de Innovación Docente de la US Esta obra se distribuye con la licencia Creative Commons 
de los discentes vinculando el estudio de la Historia Antigua (concretamente del Antiguo Egipto) con noticias muy recientes. Esto hace que los alumnos perciban que la "vetusta" Egiptología es una disciplina científica que sigue teniendo importancia social y cultural en la actualidad.

No obstante, ha habido varios aspectos sobre los que he tenido dudas a lo largo de las sesiones. Por supuesto, no se trata de que no hayan funcionado y, por ende, no sirvan. Creo que, de haber tenido más tiempo para preparar el diseño del CIMA y más experiencia en el aula en lo que respecta a la aplicación de docencia innovadora, estas dudas se habrían ido disipando. A saber:

- En el tema del Antiguo Egipto, hay contenidos del proyecto docente que no he podido ver por falta de tiempo. Es cierto que se trataban de contenidos secundarios, pero, por mi forma de ser, no me gusta excluir información.

- El hecho de presentar frecuentemente problemas y preguntas a los estudiantes me ha llevado a pensar si no estarían cansados de este recurso. Creo que no o, al menos, si les ha resultado fatigoso, no se han atrevido a comunicármelo.

- Hay algunas actividades que me han parecido repetitivas y/o generadoras de hastío (sobre todo, los visionados de documentales). Esto me sirve para aprender, pues, para próximos CIMAs, intentaré abrir el abanico de ejercicios.

- En un principio, la semipresencialidad me generó dudas, pero el chat de Collaborate ha funcionado muy bien y se han respetado los turnos de palabra.

- El análisis en pequeños grupos previo a la puesta en común de todos los estudiantes. Como acabo de comentar, debido a los protocolos sanitarios en el aula a colación de la pandemia del SARS-CoV-2 no me he atrevido a juntar a los alumnos que asistían a la clase

Ciclos de Mejora en el Aula (2020). Experiencias de Innovación Docente de la US Esta obra se distribuye con la licencia Creative Commons 
de manera presencial. Asimismo, desconozco si a través de Enseñanza Virtual se pueden conformar grupos para los alumnos que seguían la clase desde internet. Por ello, decidí que, lamentablemente, estos análisis de imágenes/textos/mapas se realizarían de forma individual.

\section{Evaluación del aprendizaje de los estudiantes}

Una vez analizados sucintamente los factores docentes relativos a la metodología y a los contenidos, es el momento de adentrarnos en el último de ellos: la evaluación. En mi opinión, es totalmente incongruente haber llevado a cabo un cambio en nuestro modelo metodológico, una jerarquización de contenidos en estructurantes y secundarios y toda una secuenciación de actividades de contraste, y que dichos cambios, con sus correspondientes profundas reflexiones académicas, no vayan aparejados de una transición en el sistema de evaluación.

La aplicación de este CIMA sienta las bases para realizar una verdadera evaluación continua de los estudiantes: mediante los cuestionarios de diagnóstico inicial y final y las diferentes secuencias de actividades podemos hacernos una idea de cómo ha evolucionado el aprendizaje de éstos. Es decir, la evaluación como camino y no como simple calificación (Rivero y Porlán, 2017).

Mediante la clasificación en diferentes grados de complejidad de los modelos de ideas detectados de los discentes a través de las preguntas de los cuestionarios de diagnóstico inicial y final podemos ir estableciendo las denominadas "escaleras de aprendizajes inicial y final" (Rivero y Porlán, 2017), respectivamente. De este modo, somos capaces de inferir de dónde parten cognitivamente nuestros alumnos individualizados y a dónde han sido capaces de llegar tras el ciclo de mejora. Como veremos en las siguientes tablas y figuras, la evolución de los modelos previos de los estudiantes de la asignatura Historia Antigua y

Ciclos de Mejora en el Aula (2020). Experiencias de Innovación Docente de la US Esta obra se distribuye con la licencia Creative Commons 
Medieval es significativamente palpable. De hecho, en algunas ocasiones, han llegado a superar el conocimiento que había estipulado como adecuado, siendo capaces de relacionar dichos modelos con otros acontecimientos 0 procesos históricos.

Tabla 7. Modelos de ideas detectados sobre la tercera pregunta de los cuestionarios de diagnóstico inicial y final

\begin{tabular}{|l|}
\hline \multicolumn{1}{|c|}{ Modelos de ideas detectados } \\
\hline $\begin{array}{l}\text { A = Valoración, sin argumentar, de la importancia de la geografía en la } \\
\text { evolución política de Egipto }\end{array}$ \\
\hline $\begin{array}{l}\text { B = Explicación unicausal: unificación debida a la obtención de materias } \\
\text { primas localizadas en diversas zonas geográficas del valle }\end{array}$ \\
\hline $\begin{array}{l}\text { C = Puesta en valor de las diferencias geográficas entre el Alto y el Bajo } \\
\text { Egipto }\end{array}$ \\
\hline $\begin{array}{l}\text { D = Respuesta académica ideal: Modelo C + la idea de que el proceso } \\
\text { de unificación tiene lugar desde el Alto hacia el Bajo Egipto, presentado } \\
\text { analogías geográficas con la revolución urbana en Mesopotamia }\end{array}$ \\
\hline $\begin{array}{l}\text { E = Modelo D + observación de las excepciones que van del Bajo al Alto } \\
\text { Egipto. Este modelo sobrepasa el “conocimiento adecuado". }\end{array}$ \\
\hline
\end{tabular}

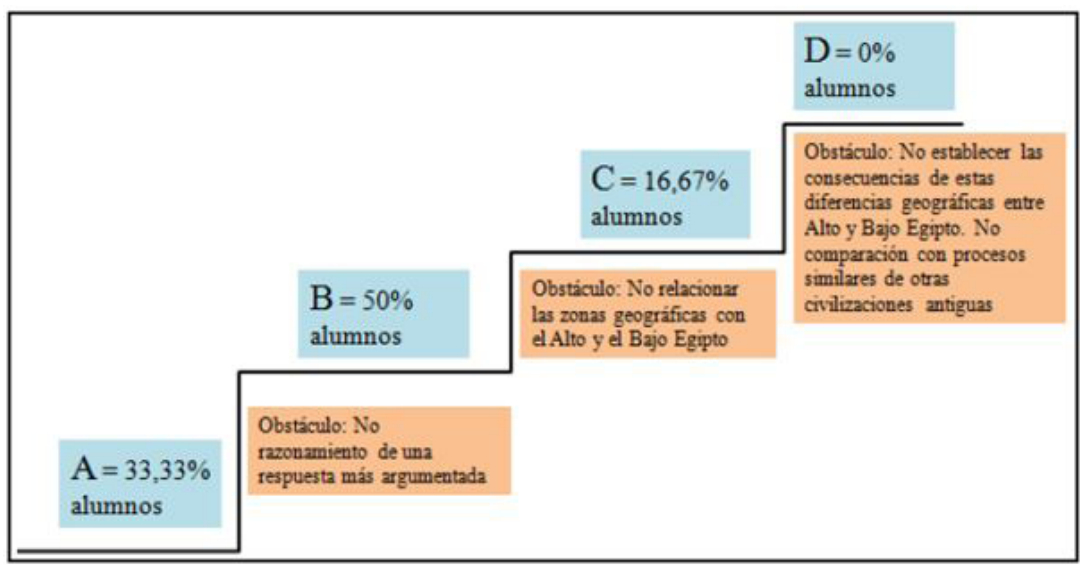

Figura 3. Escalera de aprendizaje correspondiente a la tercera pregunta del cuestionario de diagnóstico inicial

Ciclos de Mejora en el Aula (2020). Experiencias de Innovación Docente de la US Esta obra se distribuye con la licencia Creative Commons 


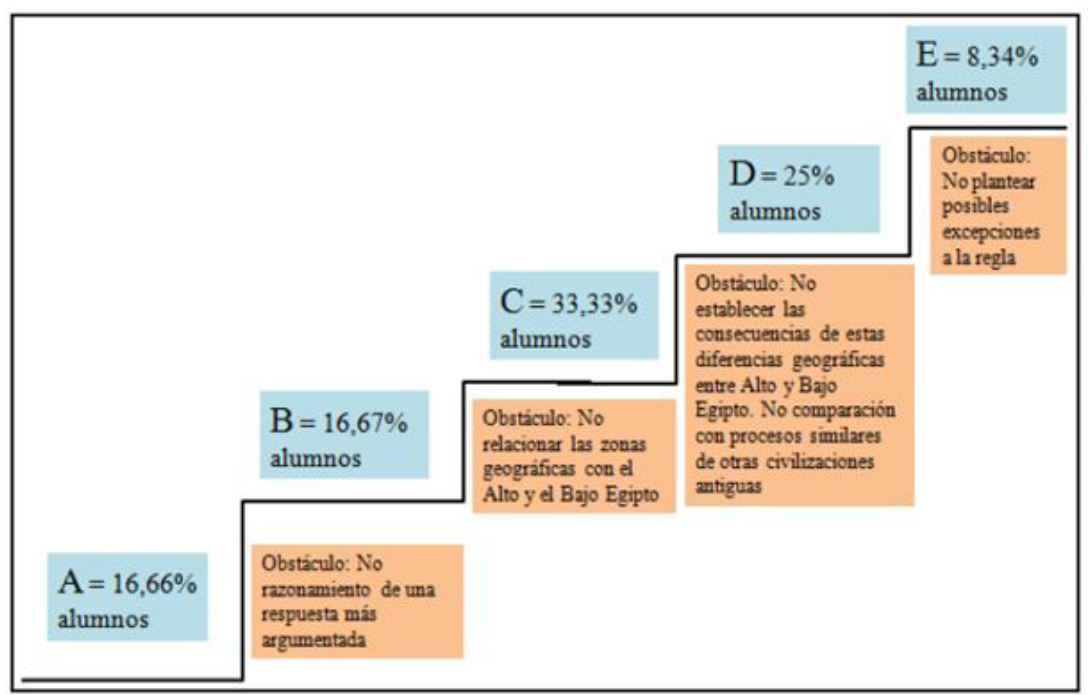

Figura 4. Escalera de aprendizaje correspondiente a la tercera pregunta del cuestionario de diagnóstico final

Como se puede deducir, cada peldaño de la escalera se corresponde con un modelo de idea. A su vez, se han destacado el porcentaje de los discentes que se encuentran en cada peldaño y aquellos obstáculos que impiden que el estudiante suba al siguiente -es justamente ahí donde se deben centrar las diferentes actividades de contraste del CIMA-. Por ejemplo, si analizamos la Figura 3, podemos observar que la mayoría de los alumnos, concretamente un $50 \%$, se ubican en el modelo de idea B. ¿Qué es lo que les frena su avance cognitivo hacia el siguiente peldaño o modelo de idea? Al ver la descripción del modelo de idea C (Tabla 7), somos capaces de deducir que este $50 \%$ del alumnado no es capaz de relacionar las zonas geográficas del valle del Nilo con conceptos como Alto y Bajo Egipto. Este sería precisamente el obstáculo sobre el que habría que incidir mediante una serie de actividades de contraste. De hecho, en la Figura 4 vemos que en el modelo de idea B sólo permanece un $16,67 \%$ de los discentes. Los restantes estudiantes que se encontraban en dicho peldaño han sido capaces de superar el impedimento mencionado. 
Además, realizadas estas escaleras, podemos establecer un cuadro de evolución de cada alumno (Tabla 8).

Tabla 8. Cuadro de evolución o resumen de la evolución individual del aprendizaje del alumnado

\begin{tabular}{|c|c|c|c|c|c|c|c|c|c|c|c|c|c|c|c|c|}
\hline & \multicolumn{2}{|c|}{ PREGUNTA 1 } & \multicolumn{2}{|c|}{ PREGUNTA 2 } & \multicolumn{2}{|c|}{ PREGUNTA 3 } & \multicolumn{2}{|c|}{ PREGUNTA 4 } & \multicolumn{3}{|c|}{ PREGUNTA 5 } \\
\hline & I & F & P & I & F & P & I & F & P & I & F & P & I & F & P \\
\hline ESTUDIANTE 1 & $\mathrm{B}$ & $\mathrm{C}$ & $\uparrow$ & $\mathrm{A}$ & $\mathrm{B}$ & $\uparrow$ & $\mathrm{A}$ & $\mathrm{A}$ & $=$ & $\mathrm{B}$ & $\mathrm{C}$ & $\uparrow$ & $\mathrm{A}$ & $\mathrm{C}$ & $\uparrow \uparrow$ \\
\hline ESTUDIANTE 2 & $\mathrm{C}$ & $\mathrm{C}$ & $=$ & $\mathrm{B}$ & $\mathrm{B}$ & $=$ & $\mathrm{B}$ & $\mathrm{D}$ & $\uparrow \uparrow$ & $\mathrm{B}$ & $\mathrm{B}$ & $=$ & $\mathrm{A}$ & $\mathrm{D}$ & $\uparrow \uparrow \uparrow$ \\
\hline ESTUDIANTE 3 & $\mathrm{B}$ & $\mathrm{B}$ & $=$ & $\mathrm{C}$ & $\mathrm{D}$ & $\uparrow$ & $\mathrm{B}$ & $\mathrm{C}$ & $\uparrow$ & $\mathrm{C}$ & $\mathrm{C}$ & $=$ & $\mathrm{B}$ & $\mathrm{B}$ & $=$ \\
\hline ESTUDIANTE 4 & $\mathrm{A}$ & $\mathrm{C}$ & $\uparrow \uparrow$ & $\mathrm{C}$ & $\mathrm{D}$ & $\uparrow$ & $\mathrm{B}$ & $\mathrm{B}$ & $=$ & $\mathrm{A}$ & $\mathrm{C}$ & $\uparrow \uparrow$ & $\mathrm{A}$ & $\mathrm{A}$ & $=$ \\
\hline ESTUDIANTE 5 & $\mathrm{B}$ & $\mathrm{D}$ & $\uparrow \uparrow$ & $\mathrm{A}$ & $\mathrm{B}$ & $\uparrow$ & $\mathrm{A}$ & $\mathrm{A}$ & $=$ & $\mathrm{B}$ & $\mathrm{C}$ & $\uparrow$ & $\mathrm{C}$ & $\mathrm{D}$ & $\uparrow$ \\
\hline ESTUDIANTE 6 & $\mathrm{A}$ & $\mathrm{C}$ & $\uparrow \uparrow$ & $\mathrm{A}$ & $\mathrm{C}$ & $\uparrow \uparrow$ & $\mathrm{A}$ & $\mathrm{C}$ & $\uparrow \uparrow$ & $\mathrm{A}$ & $\mathrm{C}$ & $\uparrow \uparrow$ & $\mathrm{C}$ & $\mathrm{D}$ & $\uparrow$ \\
\hline ESTUDIANTE 7 & $\mathrm{C}$ & $\mathrm{D}$ & $\uparrow$ & $\mathrm{B}$ & $\mathrm{C}$ & $\uparrow$ & $\mathrm{B}$ & $\mathrm{C}$ & $\uparrow$ & $\mathrm{B}$ & $\mathrm{B}$ & $=$ & $\mathrm{B}$ & $\mathrm{C}$ & $\uparrow$ \\
\hline ESTUDIANTE 8 & $\mathrm{D}$ & $\mathrm{D}$ & $=$ & $\mathrm{D}$ & $\mathrm{D}$ & $=$ & $\mathrm{C}$ & $\mathrm{E}$ & $\uparrow \uparrow$ & $\mathrm{C}$ & $\mathrm{C}$ & $=$ & $\mathrm{D}$ & $\mathrm{D}$ & $=$ \\
\hline ESTUDIANTE 9 & $\mathrm{D}$ & $\mathrm{D}$ & $=$ & $\mathrm{C}$ & $\mathrm{D}$ & $\uparrow$ & $\mathrm{B}$ & $\mathrm{B}$ & $=$ & $\mathrm{C}$ & $\mathrm{C}$ & $=$ & $\mathrm{B}$ & $\mathrm{B}$ & $=$ \\
\hline & $\ldots$ & $\ldots$ & $\ldots$ & $\ldots$ & $\ldots$ & $\ldots$ & $\ldots$ & $\ldots$ & $\ldots$ & $\ldots$ & $\ldots$ & $\ldots$ & $\ldots$ & $\ldots$ & $\ldots$ \\
\hline
\end{tabular}

\section{Conclusiones finales y evaluación del Ciclo de Mejora en el Aula}

La realización de este CIMA me ha servido para darme cuenta de las dinámicas jerárquicas inconscientemente asumidas que se establecen en el aula. Ciertamente, tenía asumido que los asistentes a mis clases asumían un rol meramente pasivo y que mi labor consistía en dar las explicaciones teóricas pertinentes como agente activo para que los alumnos alcanzaran los objetivos esperados. ¿Consecuencias? Poca asistencia a clase, poco margen de participación del alumnado, sensación de tedio, frustración al corregir los exámenes y comprobar que muy pocas personas habían logrado dichos objetivos deseados, etc.

Sin embargo, con la aplicación de este CIMA y con las sesiones del CGDU he sido por primera vez consciente de que, efectivamente, los alumnos no son "recipientes 
vacíos" que hay que rellenar con ingentes contenidos históricos -en mi caso particular-, sino que éstos ya parten de modelos cognitivos previos -más o menos acertados o errados- que, nosotros, como docentes, debemos conocer por varios motivos: en primer lugar, por una razón de respeto al estudiante (tener presente que estamos tratando con personas que, generalmente, tienen una predisposición activa a aprender); en segundo lugar como estrategia para establecer una oportuna metodología con el objetivo de que se llegue a los conocimientos esperados al final de la asignatura; y finalmente, para motivar al discente. Por ello, aunque en futuras asignaturas no pueda realizar un CIMA en su integridad por factores puramente externos (como la falta de tiempo y autonomía al ser contratado predoctoral), sí que tengo claro que voy a llevar a cabo los cuestionarios de diagnóstico inicial y final desarrollados en este ciclo. Esto me servirá para poder incidir en aquellos contenidos que presenten mayores dificultades de comprensión.

Asimismo, voy a incorporar algunas actividades de contraste mencionadas en anteriores apartados, como comentarios y análisis de mapas, elementos iconográficos y noticias contemporáneas que se puedan relacionar con la Historia Antigua. Considero que han sido las actividades que mejor han funcionado y que han ayudado enormemente a los estudiantes a lograr la evolución de sus ideas previas en conocimiento académico e incluso personal. Hay una premisa que, en mi opinión, no se nos debe olvidar a los docentes: en el fin último de la Universidad debe primar la formación de individuos como parte insustituible del colectivo social antes que la mera formación de especialistas-técnicos.

Ciclos de Mejora en el Aula (2020). Experiencias de Innovación Docente de la US Esta obra se distribuye con la licencia Creative Commons 
Palabras clave: Historia Antigua y Medieval, Grado en Historia del Arte, Docencia universitaria, Experimentación docente universitaria, Egipto faraónico.

Keywords: Ancient and Medieval History, Degree in Art History, University teaching, University teaching experimentation, Pharaonic Egypt.

\section{Referencias bibliográficas}

Bain, K. (2006). Lo que hacen los mejores profesores universitarios. Valencia: Publicaciones de la Universidad de Valencia.

De Alba, N. y Porlán, R. (2017). La metodología de enseñanza. En R. Porlán (Coord.), Enseñanza Universitaria. Cómo mejorarla (págs. 37-54). Madrid: Ediciones Morata.

Drago, C.; Espejo, R. y González, J. (2015). ¿Qué significa ser profesor universitario? Un enfoque a través de declaraciones de filosofía de enseñanza-aprendizaje. Docencia Universitaria, 16, 87-102.

Duarte, O. (2015). Los ciclos de mejora como hipótesis de progresión del modelo didáctico de investigación. En R. Porlán y E. Navarro (Coords.), III Jornadas de Docencia Universitaria (págs. 72-85). Sevilla: Instituto de Ciencias de la Educación de la Universidad de Sevilla.

Finkel, D. (2008). Dar clase con la boca cerrada. Valencia: Publicaciones de la Universidad de Valencia.

García Pérez, F. F. (2000). Los modelos didácticos como instrumento de análisis y de intervención en la realidad educativa. Biblio 3W. Revista Bibliográfica de Geografia y Ciencias Sociales, V(207) (link: http://www.ub.edu/ geocrit/b3w-207.htm).

Karm, M. (2010). Reflection tasks in Pedagogical Training Courses. International Journal for Academic Development, 15(3), 203-214.

Rivero, A. y Porlán, R. (2017). La evaluación en la enseñanza universitaria. En R. Porlán (Coord.), Enseñanza Universitaria. Cómo mejorarla (págs. 73-92). Madrid: Ediciones Morata.

Ciclos de Mejora en el Aula (2020). Experiencias de Innovación Docente de la US Esta obra se distribuye con la licencia Creative Commons 